\title{
Effect of reduced energy density of close-up diets on metabolites, lipolysis and gluconeogenesis in Holstein cows
}

\author{
Wenming Huang ${ }^{1,2}$, Libin Wang ${ }^{1,2}$, Shengli $\mathrm{Li}^{2}$, and Zhijun Cao ${ }^{2, *}$
}

* Corresponding Author: Zhijun Cao Tel: +86-10-62733746, Fax: +86-10-62733746

E-mail: caozhijun@cau.edu.cn

${ }^{1}$ Department of Animal Science, College of Animal Science, Southwest University, Chongqing 402460, China

2 State Key Laboratory of Animal Nutrition, College of Animal Science and Technology, China Agricultural University, Beijing 100193, China

ORCID

Wenming Huang

https://orcid.org/0000-0002-0313-419X

Libin Wang

https://orcid.org/0000-0002-3446-4722 Shengli Li

https://orcid.org/0000-0002-8494-7474

Zhijun Cao

https://orcid.org/0000-0002-5519-9462

Submitted Aug 21, 2018; Revised Nov 11, 2018; Accepted Dec 20, 2018
Objective: An experiment was conducted to determine the effect of reduced energy density of close-up diets on metabolites, lipolysis and gluconeogenesis in cows during the transition period.

Methods: Thirty-nine Holstein dry cows were blocked and assigned randomly to three groups, fed a high energy density diet (HD, $1.62 \mathrm{Mcal}$ of net energy for lactation $\left[\mathrm{NE}_{\mathrm{L}}\right] / \mathrm{kg}$ dry matter $[\mathrm{DM}])$, a medium energy density diet ( $\left.\mathrm{MD}, 1.47 \mathrm{Mcal} \mathrm{NE}_{\mathrm{I}} / \mathrm{kg} \mathrm{DM}\right)$, or a low energy density $\operatorname{diet}\left(\mathrm{LD}, 1.30 \mathrm{Mcal} \mathrm{NE}_{\mathrm{I}} / \mathrm{kg} \mathrm{DM}\right.$ ) prepartum; they were fed the same lactation diet to 28 days in milk (DIM). All the cows were housed in a free-stall barn and fed ad libitum.

Results: The reduced energy density diets decreased the blood insulin concentration and increased nonesterified fatty acids (NEFA) concentration in the prepartum period $(\mathrm{p}<0.05)$. They also increased the concentrations of glucose, insulin and glucagon, and decreased the concentrations of NEFA and $\beta$-hydroxybutyrate during the first 2 weeks of lactation $(p<0.05)$. The plasma urea nitrogen concentration of both prepartum and postpartum was not affected by dietary energy density $(p>0.05)$. The dietary energy density had no effect on mRNA abundance of insulin receptors, leptin and peroxisome proliferator-activated receptor- $\gamma$ in adipose tissue, and phosphoenolpyruvate carboxykinase, carnitine palmitoyltransferase- 1 and peroxisome proliferator-activated receptor- $\alpha$ in liver during the transition period $(\mathrm{p}>0.05)$. The HD cows had higher mRNA abundance of hormone-sensitive lipase at 3 DIM compared with the MD cows and LD cows $(p=0.001)$. The mRNA abundance of hepatic pyruvate carboxykinase at 3 DIM tended to be increased by the reduced energy density of the close-up diets $(\mathrm{p}=0.08)$.

Conclusion: The reduced energy density diet prepartum was effective in controlling adipose tissue mobilization and improving the capacity of hepatic gluconeogenesis postpartum.

Keywords: Transition Cow; Dietary Energy Density; Lipolysis, Gluconeogenesis; Blood Metabolites

\section{INTRODUCTION}

The transition period, from $21 \mathrm{~d}$ before to $21 \mathrm{~d}$ after parturition, is the most stressful time in the production cycle of dairy cows because of depressed dry matter intake (DMI) and marked changes in metabolism that support late gestation, parturition and the onset of milk synthesis [1-3]. The abrupt increase in energy demand and low DMI after parturition result in a negative energy balance (NEB). The DMI rather than milk yield is the major driver of NEB [4]. Therefore, nutritional management during the transition period designed to increase postpartum DMI may be a potential strategy to alleviate the negative effect of NEB on performance, as well as related metabolic disorders. Efficient gluconeogenesis is the major pathway used by dairy cows to maintain an adequate glucose supply to the mammary gland $[5,6]$. When gluconeogenesis is insufficient, mobilization of body fat reserves is the main way used to 
meet the energy requirement of high milk production during early lactation. Blood nonesterified fatty acids (NEFA) concentrations are used as an indirect measure of the mobilization of triacylglycerol from adipose tissue [7], and NEFA are taken up proportionally by the liver [8]. Extensive lipolysis is associated with postpartum metabolic disorders such as fatty liver and ketosis $[9,10]$. Fatty liver reduces the capacity for liver gluconeogenesis, and this will intensify NEB and lipolysis.

Earlier strategies focused on feeding energy-dense diets and maximizing DMI prepartum; they were aimed at supporting development of the conceptus and mammary gland, and preparing dry cows for better adaptation to the early-lactation diet $[7,11]$. In contrast to this viewpoint, in the past 15 years, some studies have shown that overconsumption of energy prepartum often results in a slower increase in DMI postpartum when compared with cows on a restricted intake [12-14] or those fed on a low energy density diet containing wheat straw [10]. Most of the above studies used moderate or high energy density diets with restricted DMI to control energy intake, or the cows were housed in a tie-stall barn. However, cows in the transition period on commercial farms normally have bunk space with free access to feed and water, instead of being restricted in a tie-stall barn with limited access to feed.

It is very common to use moderate or even high energy density transition diets on Chinese dairy farms and the incidence of metabolic diseases is sometimes very high. However, China is short of high quality forage and abundant in low quality forage (Leymus chinensis hay, corn stover and wheat straw). In our previous study, the prepartum dairy cows fed lower energy diets containing more Leymus chinensis hay had lower DMI and energy intake prepartum, but had higher milk yield and DMI postpartum, and lost numerically less body weight (BW) and body condition score (BCS) postpartum, compared with dairy cows fed higher energy diets prepartum [3]. The objective of this study was to investigate further the effect of dietary energy density in the close-up dry period (the last $3 \mathrm{wks}$ prepartum) on blood metabolites related to energy balance (EB), and the mRNA abundance of rate-limiting enzymes with regard to lipolysis and gluconeogenesis for multiparous Holstein cows fed ad libitum and housed in a free-stall barn.

\section{MATERIALS AND METHODS}

\section{Animal care}

Animal care and use were approved and conducted in accordance with the practices outlined in the Guide for the Care and Use of Agriculture Animals in Agriculture Research and Teaching [15].

\section{Animals and design}

Thirty-nine multiparous Holstein cows were grouped according to milk production in the first 3 months of the previous parity, parity, BW, BCS and expected calving date, and assigned randomly to one of three dietary treatments. From dry-off to $22 \mathrm{~d}$ before expected parturition, all cows were fed the same far-off diet (net energy for lactation $\left[\mathrm{NE}_{\mathrm{L}}\right] 1.30 \mathrm{Mcal} / \mathrm{kg}$ dry matter [DM], Table 1). From $21 \mathrm{~d}$ before the expected day of calving until parturition, the cows were blocked and assigned randomly to three groups, fed a high energy density diet (HD treatment, $\mathrm{n}=13 ; 1.62 \mathrm{Mcal} \mathrm{NE}_{\mathrm{L}} / \mathrm{kg} \mathrm{DM} ; 14.0 \%$ crude protein $[\mathrm{CP}]$ ), a medium energy density diet (MD treatment, $\mathrm{n}$ $=13 ; 1.47 \mathrm{Mcal} \mathrm{NE}_{\mathrm{L}} / \mathrm{kg} \mathrm{DM} ; 14.0 \% \mathrm{CP}$ ), or a low energy density diet ( $\mathrm{LD}$ treatment, $\mathrm{n}=13 ; 1.30 \mathrm{Mcal} \mathrm{NE}_{\mathrm{L}} / \mathrm{kg} \mathrm{DM} ; 14.0 \%$ CP; Table 1). Different amounts of water were added to each of the three diets to adjust the DM content to within $51 \%$ to $52 \%$. After parturition, all the cows were provided with the same lactation diet (Table 1) to 28 day in milk (DIM).

The details of animal management and diets were the same as in our previous research [3]. In brief, cows were housed in a free-stall barn with a delivery room, and were fed the diets as a total mixed ration ad libitum throughout the experiment. Feed was offered once daily (at 16.00 hours) prepartum, and twice (at 07.30 and 14.30 hours) postpartum. Cows were milked three times daily.

\section{Blood collection and analyses of metabolites}

Blood samples were obtained from the coccygeal vessel at 0900 $\mathrm{h}$ on $\mathrm{d}-21,-14,-7,7,14,21$, and 28 relative to parturition, and immediately after parturition. Blood was taken into evacuated serum separator tubes containing clot activator and into evacuated plasma tubes containing ethylenediaminetetraacetic acid. Tubes for plasma preparation were put on ice immediately after sampling and centrifuged at $3,000 \times \mathrm{g}$ for $15 \mathrm{~min}$ at $4^{\circ} \mathrm{C}$. Tubes for serum preparation were allowed to clot for 30 $\mathrm{min}$ at room temperature before centrifugation for $15 \mathrm{~min}$ at $2,000 \times g$ at $4^{\circ} \mathrm{C}$. Plasma and serum were aliquoted into $1.5-\mathrm{mL}$ centrifuge tubes and stored at $-20^{\circ} \mathrm{C}$ until analysis. Plasma samples were sent to a clinical laboratory of the 309th Hospital (Beijing, China) for analysis of glucose, NEFA, and plasma urea nitrogen (PUN) using an autoanalyzer (ILAB 600, Instrumentation Laboratory, Lexington, MA, USA) with kits supplied by Instrumentation Laboratory. Plasma concentrations of $\beta$-hydroxybutyrate (BHBA) were measured using a BHBA kit (Sigma-Aldrich Chemical Co., Shanghai, China). Radioimmunoassay kits were used to measure serum insulin (Coat-A-Count Insulin, Siemens Medical Solutions USA Inc., Malvern, PA, USA) and plasma glucagon (Double Antibody Glucagon, Siemens Medical Solutions USA Inc., USA).

\section{Liver and adipose tissue collection and quantitative polymerase chain reaction analysis}

Five cows per treatment were selected randomly for collection of liver and adipose tissue at $1000 \mathrm{~h}$ on $\mathrm{d}-7,3$, and 14 relative to parturition. Liver tissue was sampled via puncture biopsy 
Table 1. Composition and analysis of diets fed to Holstein cows during the dry and lactating periods

\begin{tabular}{|c|c|c|c|c|c|}
\hline \multirow{2}{*}{ Item } & \multirow{2}{*}{ Far-off diet } & \multicolumn{3}{|c|}{ Close-up diets } & \multirow{2}{*}{ Lactation diet ${ }^{1)}$} \\
\hline & & HD & MD & LD & \\
\hline \multicolumn{6}{|l|}{ Ingredients (\% DM) } \\
\hline Leymus chinensis hay & 42.8 & 13.3 & 21.7 & 31.3 & - \\
\hline Alfalfa hay & - & 8.4 & 8.4 & 8.4 & 17.2 \\
\hline Whole corn silage & 24.7 & 21.0 & 21.1 & 21.0 & 21.0 \\
\hline Corn & 1.2 & 23.2 & 14.4 & 2.0 & 20.0 \\
\hline Extruded soybean & - & - & - & - & 2.6 \\
\hline Soybean meal & 2.1 & 4.5 & 4.0 & 3.7 & 5.8 \\
\hline Rapeseed meal & 4.5 & 4.0 & 4.0 & 4.0 & 1.3 \\
\hline Cottonseed meal & 5.0 & 4.0 & 4.3 & 4.5 & 1.3 \\
\hline Apple pomace & 9.0 & 5.6 & 7.4 & 11.3 & 2.5 \\
\hline Whole cottonseed & - & 3.3 & 3.3 & 3.3 & 10.4 \\
\hline Distillers dried grains with soluble & 4.1 & 4.0 & 4.0 & 4.0 & 10.0 \\
\hline Palm kernel meal & 5.1 & 3.3 & 3.3 & 3.3 & - \\
\hline Beet pulp meal & - & - & - & - & 3.5 \\
\hline Calcium carbonate & 1.2 & 1.9 & 1.9 & 1.9 & 1.0 \\
\hline Close-up premix ${ }^{2)}$ & 0.1 & 0.4 & 0.4 & 0.4 & - \\
\hline Lactation premix ${ }^{3)}$ & - & - & - & - & 0.5 \\
\hline Bergafat ${ }^{4)}$ & - & 2.2 & 0.9 & - & 1.6 \\
\hline Yeast culture ${ }^{5)}$ & 0.2 & 0.9 & 0.9 & 0.9 & 0.4 \\
\hline Sodium bicarbonate & - & - & - & - & 0.9 \\
\hline \multicolumn{6}{|l|}{ Analysis } \\
\hline DM (\%) & 51.9 & 51.5 & 51.5 & 51.6 & 52.1 \\
\hline CP $(\%$ of $D M)$ & 12.6 & 14.0 & 14.0 & 14.0 & 18.2 \\
\hline NDF (\% of DM) & 53.3 & 37.4 & 42.9 & 49.8 & 31.7 \\
\hline ADF (\% of DM) & 32.4 & 23.2 & 26.8 & 31.5 & 19.8 \\
\hline NFC ( $\%$ of DM) & 22.8 & 35.0 & 30.4 & 23.9 & 36.9 \\
\hline Crude fat ( $\%$ of DM) & 3.1 & 5.6 & 4.3 & 3.3 & 5.7 \\
\hline $\mathrm{NE}_{\mathrm{L}}(\mathrm{MJ} / \mathrm{kg} \mathrm{DM})$ & 5.4 & 6.8 & 6.2 & 5.4 & 7.2 \\
\hline ME (MJ/kg DM) & 8.7 & 10.7 & 10.0 & 8.8 & 11.1 \\
\hline
\end{tabular}

$H D$, high energy density diet; $M D$, medium energy density diet; LD, low energy density diet; DM, dry matter; $C P$, crude protein; NDF, neutral detergent fiber; $A D F$, acid detergent fiber; NFC, nonfiber carbohydrate; $\mathrm{NE}_{\mathrm{L},}$ net energy for lactation; $\mathrm{ME}$, metabolizable energy.

1) Lactation diet was fed to cows from parturition to $70 \mathrm{~d}$ in milk.

2) Close-up premix contained (per kg of premix; DM basis): 2,200,000 IU of vitamin $A, 550,000$ IU of vitamin $D_{3}, 20,000$ IU of vitamin $E, 2,000 \mathrm{mg}$ of vitamin PP, 3,750 mg $\mathrm{Cu}, 5,720 \mathrm{mg} \mathrm{Mn}, 14,850 \mathrm{mg}$ Zn, $150 \mathrm{mg} \mathrm{I}, 180 \mathrm{mg} \mathrm{Se}, 120 \mathrm{mg} \mathrm{Co}$.

3) Lactation premix contained (per kg of premix; DM basis): 1,000,000 IU of vitamin A, 280,000 IU of vitamin $\mathrm{D}_{3}, 10,000 \mathrm{IU}$ of vitamin E, 1,000 mg of vitamin PP, 3,250 mg $\mathrm{Cu}, 4,800 \mathrm{mg} \mathrm{Mn}, 12,850 \mathrm{mg}$ Zn, $140 \mathrm{mg} \mathrm{I}, 150 \mathrm{mg} \mathrm{Se}, 110 \mathrm{mg} \mathrm{Co}$

4) Fractionated palm fatty acids (Berg+Schmidt, Hamburg, Germany).

${ }^{5)}$ Diamond V XP, Diamond V Mills, Inc..

under general anesthesia and local anesthesia as described by Zom et al [16]. Subsequently, adipose tissue was sampled from the tail region between the ischium pin bone and coccygeal vertebrae as described by Goselink et al [17]. All dissected liver and adipose tissue samples were washed with normal saline and immediately snap frozen in liquid nitrogen and stored at $-80^{\circ} \mathrm{C}$ until RNA extraction.

For measurement of gene expression, frozen samples of liver and adipose tissue were ground under liquid nitrogen and total RNA was isolated using TRIzol reagent (Invitrogen, Breda, the Netherlands), following the manufacturer's instructions. To eliminate DNA contamination, the isolated RNA was subjected to an on-column DNase treatment (NucleoSpin RNA
II kit; Macherey-Nagel GmbH \& Co. KG, Duren, Germany). Reverse transcription of $1 \mu \mathrm{g}$ of total RNA was performed in a $20-\mu \mathrm{L}$ reaction using Superscript III reverse transcriptase (Invitrogen, the Netherlands) according to the manufacturer's protocol. The mRNA expression was assessed using a SYBR Premix Ex Taq II kit (TaKaRa Biotechnology Co. Ltd., Dalian, China), following the instructions. The reactions were run in triplicate on a 7500 Fast Real-Time PCR System (Applied Biosystems Deutschland GmbH, Darmstadt, Germany), and the relative expression of genes was analyzed using the $2^{-\Delta \Delta C T}$ method [18].

We measured the transcript levels of the following key enzymes related to fatty acid and energy metabolism in the liver: 
carnitine palmitoyltransferase-1 (CPT1), peroxisome proliferator-activated receptor- $\alpha$ (PPAR $\alpha$ ), pyruvate carboxykinase (PC), and phosphoenolpyruvate carboxykinase (PEPCK). In addition, the expression of hormone sensitive lipase (HSL), peroxisome proliferator-activated receptor- $\gamma(\operatorname{PPAR} \gamma)$, insulin receptor (InsR), and leptin was analyzed in adipose tissue. All the primers are presented in Table 2. Housekeeping genes ribosomal protein L19 (RPL19) and $\beta$-actin were analyzed as internal standards.

\section{Statistical analysis}

To avoid problems with fitting the covariance structure, data for blood parameters were analyzed separately for the prepartum and postpartum periods. The data for blood parameters were evaluated using the MIXED procedure of SPSS 16.0 (SPSS Inc., Chicago, IL, USA) for repeated measures with the following model: $\mathrm{Y}_{\mathrm{ikn}}=\mu+\mathrm{W}_{\mathrm{i}}+\mathrm{T}_{\mathrm{k}}+\mathrm{WT}_{\mathrm{ik}}+\mathrm{C}_{(\mathrm{ik}) \mathrm{n}}$, where $\mathrm{Y}_{\mathrm{ikn}}=$ an observation from the ith week relative to calving, kth treatment, and nth cow; $\mu=$ the grand mean; $\mathrm{W}_{\mathrm{i}}=$ effect of the ith week; $\mathrm{T}_{\mathrm{k}}=$ effect of the kth treatment; $\mathrm{WT}_{\mathrm{ik}}=$ effect of the week by treatment interaction; and $\mathrm{C}_{(\mathrm{ik}) \mathrm{n}}=$ random experimental error from the nth cow nested within the ith week and kth treatment. A repeated statement was used for variables measured over time. Covariance structures including first-order autoregressive (AR[1]), compound symmetry, and unstructured were tested. AR(1) yielded the lowest Akaike's criterion

Table 2. Sequences of the primers used for quantitative polymerase chain reaction in adipose tissue and liver

\begin{tabular}{|c|c|c|}
\hline Primer & Primer sequence $\left(5^{\prime}-3^{\prime}\right)$ & Product size (bp) \\
\hline \multirow[t]{2}{*}{$\beta$-actin } & F: TCATCACCATCGGCAATGAG & 378 \\
\hline & R: CATCGTACTCCTGCTTGCTGA & \\
\hline \multirow[t]{2}{*}{ RPL19 } & F: AGGGTACTGCCAATGCTTTAATG & 113 \\
\hline & R: CATGTGGCGGTCAATCTTCTT & \\
\hline \multirow[t]{2}{*}{$P C$} & F: CCCACAGCTTCAACAAACTCTT & 236 \\
\hline & R: GATGTCCATGCCATTCTCCTT & \\
\hline \multirow[t]{2}{*}{ PEPCK } & F: CCAACTCACGGTTCTGCACT & 225 \\
\hline & R: GCATGATGACTTTGCCCTTGT & \\
\hline \multirow[t]{2}{*}{ CPT1 } & F: GCAGCGTTCTTCGTGACGTTA & 115 \\
\hline & R:ACCTGTCGAAACACCTGCCAT & \\
\hline \multirow[t]{2}{*}{ PPAR $\alpha$} & F: GAGCTGGACGACAGTGATATTT & 144 \\
\hline & R:ATGGTTGTTCTGTAGGTGGAGT & \\
\hline \multirow[t]{2}{*}{ HSL } & F: ACGAGCCTTACCTCAAGAGCTG & 124 \\
\hline & R: CAGCAGTAGGCATAGGAGCACTC & \\
\hline \multirow[t]{2}{*}{ PPAR $\gamma$} & F: CCCTTTGGTGACTTTATGGAG & 155 \\
\hline & R: TGTATGTCCTCAATGGGCTTC & \\
\hline \multirow[t]{2}{*}{ InsR } & F: AGCTGGAGGAGTCCTCGTTC & 113 \\
\hline & R:TGTCACATTCCCCACGTCA & \\
\hline \multirow[t]{2}{*}{ LEP } & F: CTTTGGCCCTATCTGTCTTACGT & 76 \\
\hline & R:TCTTGATGAGGGTTTTGGTGTCA & \\
\hline
\end{tabular}

RPL19, ribosomal protein L 19; PC, pyruvate carboxykinase; PEPCK, phosphoenolpyruvate carboxykinase; CPT1, carnitine palmitoyltransferase-1; PPAR $\alpha$, peroxisome proliferator-activated receptor- $\alpha$; HSL, hormone sensitive lipase; PPAR $\gamma$, peroxisome proliferator-activated receptor- $\gamma$; InsR, insulin receptor; LEP, leptin. and was finally used in our model. The data on gene expression were evaluated by the one-way ANOVA procedure of SPSS 16.0 (SPSS Inc., USA). Tukey's procedure for comparison of multiple means was used to separate treatment means. Least squares means were computed and are presented throughout. A value of $\mathrm{p}<0.05$ was set as the significance level.

\section{RESULTS}

\section{Blood metabolites and hormones}

The blood glucose concentration both prepartum and on the day of calving was not affected by the dietary energy density ( $p>0.05$; Table 3$)$. The glucose concentration for the HD treatment was lower than for the MD treatment $(\mathrm{p}<0.05)$, and numerically lower than that for the LD treatment $(\mathrm{p}>0.05)$ during the first $4 \mathrm{wk}$ of lactation. The prepartum concentration of insulin for the LD treatment was lower than that of the $\mathrm{HD}$ and MD treatments $(\mathrm{p}<0.05)$. After parturition, the LD and $\mathrm{MD}$ treatments gave higher insulin concentrations during the first $2 \mathrm{wk}$ of lactation $(\mathrm{p}<0.05)$, but there was no significant difference among the three treatments during the first 4 wk of lactation ( $p>0.05)$. There was no significant difference among the three treatments in glucagon concentration before calving and on the day of calving ( $p>0.05)$. The glucagon concentration for the HD treatment was lower than those for the $\mathrm{MD}$ and $\mathrm{LD}$ treatments during the first 2 wk of lactation ( $\mathrm{p}<$ 0.05 ), but there was no significant difference among the three treatments during the first $4 \mathrm{wk}$ of lactation $(\mathrm{p}>0.05)$.

The LD treatment had higher prepartum NEFA concentration when compared with HD treatment $(\mathrm{p}<0.05)$. After parturition, the LD treatment had lower NEFA concentration when compared with the HD treatment during the first $2 \mathrm{wk}$ and $4 \mathrm{wk}$ of lactation $(\mathrm{p}<0.05)$. There was no significant difference among the three treatments in BHBA concentration before calving and on the day of calving $(\mathrm{p}>0.05)$. The HD treatment gave higher BHBA concentration than the MD treatment and LD treatment during the first 2 wk of lactation $(\mathrm{p}<$ 0.05 ), but there was no significant difference among the three treatments during the first $4 \mathrm{wk}$ of lactation $(\mathrm{p}>0.05)$. The PUN concentration both prepartum and postpartum was not affect by dietary energy density $(\mathrm{p}>0.05)$.

\section{Expression of genes related to lipolysis and gluconeogenesis}

The dietary energy density had no effect on the mRNA abundance of InsR, leptin, and PPAR $\gamma$ in adipose tissue both prepartum and postpartum ( $p>0.05$; Table 4$)$. The HD treatment gave higher mRNA abundance of HSL at 3 DIM compared with the MD and LD treatments ( $p=0.001)$, but there was no significant difference at $7 \mathrm{~d}$ before calving and 14 DIM among the three treatments $(p>0.05)$. The mRNA abundance of hepatic PEPCK, PC, CPT1, and PPAR $\alpha$, both prepartum and 
Table 3. Effect of close-up dietary energy density on blood metabolites and hormones in Holstein cows

\begin{tabular}{|c|c|c|c|c|c|c|c|}
\hline \multirow{2}{*}{ Item } & \multicolumn{3}{|c|}{ Dietary treatments } & \multirow{2}{*}{ SEM } & \multicolumn{3}{|c|}{$p$-value } \\
\hline & HD & MD & LD & & Diets & Time & Interaction \\
\hline \multicolumn{8}{|c|}{ Glucose (mmol/L) } \\
\hline $0 d$ & 7.92 & 7.64 & 6.98 & 0.22 & 0.36 & - & - \\
\hline 1 to $2 w k$ & $3.27^{b}$ & $3.79^{\mathrm{a}}$ & $3.65^{a b}$ & 0.08 & 0.02 & 0.98 & 0.59 \\
\hline 1 to 4 wk & $3.47^{b}$ & $3.71^{\mathrm{a}}$ & $3.67^{\mathrm{ab}}$ & 0.04 & 0.04 & 0.71 & 0.13 \\
\hline-2 to -1 wk & $16.56^{\mathrm{a}}$ & $16.16^{\mathrm{a}}$ & $14.43^{b}$ & 0.41 & 0.01 & 0.02 & 0.98 \\
\hline $0 d$ & 4.94 & 5.01 & 5.62 & 0.22 & 0.40 & - & - \\
\hline 1 to 2 wk & $6.51^{b}$ & $8.42^{\mathrm{a}}$ & $8.77^{\mathrm{a}}$ & 0.52 & 0.01 & 0.008 & 0.046 \\
\hline 1 to 4 wk & 10.06 & 10.59 & 10.88 & 0.65 & 0.66 & $<0.001$ & 0.26 \\
\hline \multicolumn{8}{|l|}{ Glucagon (pg/mL) } \\
\hline \multicolumn{8}{|l|}{ NEFA ( $\mu E q / L)$} \\
\hline-2 to -1 wk & $222.78^{b}$ & $251.77^{\mathrm{ab}}$ & $283.50^{\mathrm{a}}$ & 11.89 & 0.005 & $<0.001$ & 0.59 \\
\hline $0 d$ & 463.88 & 497.23 & 541.44 & 25.79 & 0.49 & - & - \\
\hline 1 to $2 \mathrm{wk}$ & $605.67^{\mathrm{a}}$ & $526.99^{\mathrm{ab}}$ & $464.78^{b}$ & 32.62 & 0.02 & 0.15 & 0.92 \\
\hline 1 to 4 wk & $496.03^{a}$ & $452.39^{\mathrm{ab}}$ & $399.47^{b}$ & 20.15 & 0.01 & $<0.001$ & 0.82 \\
\hline \multicolumn{8}{|l|}{ BHBA (mmol/L) } \\
\hline-2 to -1 wk & 0.57 & 0.59 & 0.51 & 0.02 & 0.15 & 0.02 & 0.48 \\
\hline $0 d$ & 0.58 & 0.55 & 0.65 & 0.3 & 0.72 & - & - \\
\hline 1 to 2 wk & $0.67^{\mathrm{a}}$ & $0.52^{b}$ & $0.54^{b}$ & 0.02 & 0.03 & 0.69 & 0.61 \\
\hline 1 to 4 wk & 0.66 & 0.59 & 0.60 & 0.02 & 0.32 & 0.11 & 0.58 \\
\hline
\end{tabular}

HD, high energy density diet; MD, medium energy density diet; LD, low energy density diet; SEM, standard error of the mean; NEFA, nonesterified fatty acids; BHBA, $\beta$-hydroxybutyrate; PUN, plasma urea nitrogen.

$a, b$ Values within a row with different superscripts differ significantly at $p<0.05$.

postpartum, was not affected by dietary energy density $(\mathrm{p}>0.05$; Table 5). The mRNA abundance of hepatic PC at 3 DIM tended to be increased by the reduced energy density of close-up diets $(\mathrm{p}=0.08)$.

\section{DISCUSSION}

\section{Blood metabolites and hormones}

Prepartum: Diets containing a greater amount of fermentable starch can result in increased blood glucose concentration in cattle. Some studies have demonstrated that prepartum dairy cows fed higher energy diets had higher blood glucose concentrations compared with those undergoing restriction of energy intake $[10,14,19]$. In the current study, the dietary energy density did not significantly affect prepartum blood glucose concentrations. Our previous study reported that cows in all three treatment groups offered ad libitum intake during the close-up period consumed more energy relative to their requirements [3]. The positive EB prepartum could explain why there was no significant difference in blood glucose concentrations among the three treatments. The prepartum concentration of insulin in LD cows was lower than that in $\mathrm{HD}$ and MD cows. Other studies have confirmed that cows had higher blood glucose and insulin concentrations in response to greater energy intake prepartum $[10,19]$.

The prepartum concentrations of NEFA and postpartum NEFA and BHBA are usually considered important indicators of health condition and to predict disease occurrence during the periparturient period [20]. Circulating NEFA are used as an indirect measure of mobilization of triacylglycerol from adipose tissue. Compared with HD cows, the LD cows had higher blood NEFA concentration prepartum. The HD cows had higher energy intake and improved EB prepartum, which subsequently reduced fat mobilization. Others have 
Table 4. Effect of close-up dietary energy density on mRNA abundance of genes related to mobilization of adipose tissue in Holstein cows

\begin{tabular}{|c|c|c|c|}
\hline \multirow{2}{*}{ Item } & \multicolumn{3}{|c|}{ Day relative to parturition (d) } \\
\hline & -7 & 3 & 14 \\
\hline \multicolumn{4}{|l|}{ HSL } \\
\hline$H D$ & 0.26 & $0.95^{\mathrm{a}}$ & 3.30 \\
\hline MD & 0.23 & $0.48^{b}$ & 3.21 \\
\hline LD & 0.31 & $0.51^{b}$ & 2.93 \\
\hline SEM & 0.03 & 0.08 & 0.23 \\
\hline $\mathrm{p}$-value & 0.53 & 0.001 & 0.83 \\
\hline \multicolumn{4}{|l|}{ LEP } \\
\hline$H D$ & 0.08 & 0.14 & 1.13 \\
\hline MD & 0.08 & 0.08 & 0.92 \\
\hline LD & 0.09 & 0.13 & 1.08 \\
\hline SEM & 0.01 & 0.01 & 0.10 \\
\hline$p$-value & 0.87 & 0.24 & 0.73 \\
\hline \multicolumn{4}{|l|}{ InsR } \\
\hline$H D$ & 0.31 & 0.42 & 0.56 \\
\hline MD & 0.40 & 0.46 & 0.53 \\
\hline LD & 0.37 & 0.42 & 0.53 \\
\hline SEM & 0.03 & 0.09 & 0.04 \\
\hline$p$-value & 0.63 & 0.98 & 0.92 \\
\hline \multicolumn{4}{|l|}{ PPAR $\gamma$} \\
\hline$H D$ & 0.33 & 0.38 & 0.41 \\
\hline$M D$ & 0.31 & 0.34 & 0.34 \\
\hline LD & 0.34 & 0.37 & 0.39 \\
\hline SEM & 0.03 & 0.03 & 0.05 \\
\hline $\mathrm{p}$-value & 0.92 & 0.90 & 0.86 \\
\hline
\end{tabular}

$H S L$, hormone sensitive lipase; $H D$, high energy density diet; $M D$, medium energy density diet; LD, low energy density diet; SEM, standard error of the mean; LEP, leptin; InsR, insulin receptor; PPAR $\gamma$, peroxisome proliferator-activated receptor- $\gamma$.

$a, b$ Values within a column with different superscripts differ significantly at $p<0.05$.

also demonstrated that overfed cows had lower NEFA concentration than cows on restricted feed or those fed ad libitum a high forage diet $[10,19]$. The present study and others have noted that prepartum energy intake does not affect prepartum BHBA concentration, even in cows with restricted intake $[10,14]$. Douglas et al [21] reported that supplementation of fat, compared with a moderately high grain diet, did not affect prepartum blood BHBA concentration. The duration of feeding a high energy diet had no effect on blood BHBA concentration prepartum [7]. These results suggested that prepartum BHBA content for dairy cows was not affected by energy intake during the dry period.

Postpartum: All cows experienced a striking increase in blood glucose concentration at calving. Other authors have reported similar results $[10,22]$. Janovick et al [10] found that primiparous cows had lower blood glucose concentrations at parturition compared with multiparous cows, and this helped to explain the association of calving difficulty with blood glucose content. In our study, after parturition, HD cows had lower blood glucose concentrations than MD cows during the first $4 \mathrm{wk}$ of lactation, and this was consistent with our previous study
Table 5. Effect of close-up dietary energy density on mRNA abundance of genes related to hepatic gluconeogenesis in Holstein cows

\begin{tabular}{llll}
\hline \multirow{2}{*}{ Item } & \multicolumn{3}{c}{ Day relative to parturition (d) } \\
\cline { 2 - 4 } & -7 & 3 & 14 \\
\hline PEPCK & & & \\
HD & 0.28 & 0.32 & 0.29 \\
MD & 0.21 & 0.31 & 0.19 \\
LD & 0.17 & 0.42 & 0.22 \\
SEM & 0.03 & 0.04 & 0.03 \\
p-value & 0.25 & 0.39 & 0.53 \\
CPT1 & & & \\
HD & 0.51 & 0.61 & 0.54 \\
MD & 0.50 & 0.57 & 0.53 \\
LD & 0.56 & 0.80 & 0.61 \\
SEM & 0.04 & 0.11 & 0.04 \\
P-value & 0.88 & 0.74 & 0.72 \\
PC & & & \\
HD & 0.29 & 0.52 & 0.68 \\
MD & 0.31 & 0.70 & 0.59 \\
LD & 0.42 & 0.81 & 0.64 \\
SEM & 0.04 & 0.06 & 0.04 \\
P-value & 0.34 & 0.08 & 0.71 \\
PPAR & & & \\
HD & 0.57 & 0.72 & 0.55 \\
MD & 0.46 & 0.71 & 0.54 \\
LD & 0.45 & 0.80 & 0.64 \\
SEM & 0.05 & 0.07 & 0.06 \\
p-value & 0.87 & 0.82 \\
\hline PEPCK & & & \\
\hline
\end{tabular}

PEPCK, phosphoenolpyruvate carboxykinase; HD, high energy density diet; MD, medium energy density diet; LD, low energy density diet; SEM, standard error of the mean; CPT1, carnitine palmitoyltransferase-1; PC, pyruvate carboxykinase; PPAR $\alpha$, peroxisome proliferator-activated receptor- $\alpha$.

in which $\mathrm{HD}$ cows had lower lactose production and numerically lower DMI postpartum [3].

The blood insulin concentration decreased sharply at parturition for all groups in the present study, which coincided with an increased blood glucose concentration. This may be a mechanism to increase blood glucose concentration for calving. After parturition, although the insulin concentration for the three groups increased compared with the calving day, it was lower than the prepartum level. Alharthi et al [23] found both high and low BCS transition cows had lower plasma insulin concentrations on 7 and 20 DIM compared with $10 \mathrm{~d}$ before calving. Salin et al [24] suggested that the decrease in insulin concentration near calving is a major factor directing glucose to the mammary gland.

The NEB of early lactation is accompanied by an insulinresistant state in tissues such as adipose tissue and skeletal muscle to ensure that nutrients are spared to provide an adequate supply to the mammary gland. To a certain extent, therefore, a degree of insulin resistance is needed to support higher milk production in early lactation [10]. Overfeeding energy prepartum has been demonstrated to decrease the glucose clearance 
rate in response to a glucose challenge administered at $3 \mathrm{wk}$ postpartum, when compared with cows whose intake was controlled or restricted prepartum [25]. However, severe insulin resistance increases fat mobilization. Circulating NEFA are used as an indirect measure of mobilization of triacylglycerol from adipose tissue. Thus, lower responses to insulin in cows may promote greater concentrations of NEFA and BHBA, which may induce fatty liver and ketosis. Our own and other studies have demonstrated that cows overfed prepartum had higher NEFA and BHBA concentration during early lactation $[10,19]$. In our previous study, the HD cows lost numerically more BCS and BW postpartum [3].

Glucagon promotes the capacity of hepatic gluconeogenesis in early lactating cows [26]. In the current study, HD cows had a lower concentration of glucagon than the MD and $\mathrm{LD}$ cows during the first two wk of lactation, which indicated an improved gluconeogenic status and may be related to the increased production of lactose. In our previous study, the average lactose production for the LD and HD cows was 1.72 and 1.58 $\mathrm{kg} / \mathrm{d}$, respectively, during the first $3 \mathrm{wk}$ of lactation.

\section{Expression of genes related to lipolysis and gluconeogenesis}

Adipose tissue mobilization is essential for high producing dairy cows to meet the energy requirement for milk production in early lactation. HSL is the rate-limiting enzyme in lipolysis. In the present study, the mRNA abundance of HSL in adipose tissue was increased markedly for all the three groups from -7 to $14 \mathrm{~d}$ relative to calving, and it was significantly higher for HD cows than LD and MD cows at 7 DIM. These results indicated that, with the prolongation of early lactation, the amount of adipose tissue mobilization increased rapidly, especially for cows fed a high energy density diet prepartum. Over conditioned cows have larger adipocytes and are predisposed to excessive mobilization of body fat due to a higher basal and stimulated lipolytic activity of large adipocytes [27]. Jaakson et al [28] also found that over conditioning during the dry period was related to intensified lipid mobilization at the beginning of lactation. Our previous study demonstrated that the cows fed a high energy density diet showed numerically more BCS and BW prepartum, and lost numerically more BCS and BW postpartum [3].

Leptin is a hormone-inducing protein secreted by adipose tissue that plays an important role in EB and body fat stability [29]. In the present study, the mRNA abundance of leptin in adipose tissue was increased markedly for all cows from -7 to $14 \mathrm{~d}$ relative to calving, which was similar to the effect of HSL. These results also suggested that adipose tissue mobilization increases rapidly during early lactation, but the prepartum dietary energy density has no effect on mRNA abundance of leptin postpartum. Another study showed that prepartum energy level had only transient effects on the serum leptin concentration in dairy cows during the transition period [30].

CPT1 and PPAR $\alpha$ are involved in hepatic fatty acid oxidation. Their mRNA abundance is positively correlated with circulating NEFA and BHBA concentrations [31]. In the current study, although the high energy diet increased concentrations of NEFA and BHBA postpartum, it did not cause changes in mRNA expression of CPT1 and PPARa. Other research has also shown that prepartum energy supplementation does not have an effect on liver triglyceride accumulation, nor on the mRNA abundance of CPT1 and PPAR $\alpha$ [32]. If excessive lipolysis occurs during early lactation the oxidative capacity of the liver can be exceeded, resulting in liver triglyceride accumulation and ketosis, which reduces hepatic gluconeogenic capacity.

The PC catalyzes the conversion of pyruvate to oxaloacetate, and cytosolic PEPCK catalyzes the conversion of oxaloacetate to phosphoenolpyruvate. Both enzymes have been shown to respond to the onset of lactation. In the present study, the mRNA abundance of the two enzymes increased markedly for the cows given all three treatments at 3 DIM compared with $-7 \mathrm{~d}$ relative to calving. The prepartum low energy diet had a tendency to increase hepatic PC mRNA expression, which was consistent with higher postpartum blood glucose concentration and lower NEFA and BHBA concentrations in the LD cows. Other research has also shown that the abundance of hepatic PC mRNA at $1 \mathrm{~d}$ was elevated significantly when compared with $-14 \mathrm{~d}$ relative to calving, but there was no significant difference for that of hepatic PEPCK [33]. There was little difference in the abundance of PEPCK mRNA between $-7 \mathrm{~d}$ and $14 \mathrm{~d}$ relative to calving. Laguna et al [34] reported similar findings for the mRNA abundance of cytosolic PEPCK in dairy cows during the transition period. These results indicate that PC is more susceptible to EB than PEPCK, and that PEPCK is a more important rate-limiting enzyme involved in glucose production than PC. Glucagon increases the mRNA expression of gluconeogenic enzymes in the liver of early lactating cows [26]. In the current study, HD cows had a lower concentration of blood glucagon than MD and LD cows in the first 2 wk of lactation, and this was consistent with the lower mRNA abundance of PC during early lactation.

\section{CONCLUSION}

Ad libitum feeding of a reduced energy density diet during the close-up period decreased the mRNA abundance of HSL in adipose tissue, decreased the concentrations of circulating insulin, glucagon, NEFA and BHBA, and improved the mRNA abundance of hepatic PC in early lactation. These results suggested that a low energy density diet was beneficial in controlling lipolysis and promoting the capacity for hepatic gluconeogenesis postpartum. Whether the mRNA abundance of hepatic PEPCK is not susceptible to regulation by NEB needs more 
in-depth research.

\section{CONFLICT OF INTEREST}

We certify that there is no conflict of interest with any financial organization regarding the material discussed in the manuscript.

\section{ACKNOWLEDGMENTS}

This work was supported by the National Natural Science Foundation of China (31601964), State Key Laboratory of Animal Nutrition (2004DA125184F1710), Chongqing Research Program of Basic Research and Frontier Technology (cstc2017 jcyjAX0014 and cstc2018jcyjA1098), and Fundamental Research Funds for the Central Universities (XDJK2018C056). The authors greatly appreciate all the people who offered assistance in the experimental procedures and paper writing.

\section{REFERENCES}

1. Grummer RR. Impact of changes in organic nutrient metabolism on feeding the transition dairy cow. J Anim Sci 1995;73: 2820-33.

2. Drackley JK. Biology of dairy cows during the transition period: the final frontier? J Dairy Sci 1999;82:2259-73.

3. Huang W, Tian Y, Wang Y, et al. Effect of reduced energy density of close-up diets on dry matter intake, lactation performance and energy balance in multiparous Holstein cows. J Anim Sci Biotechnol 2014;5:30.

4. Grummer RR, Wiltbank MC, Fricke PM, Watters RD, Silvadel-rio N. Management of dry and transition cows to improve energy balance and reproduction. J Anim Reprod 2010;56 (Suppl):S22-8.

5. Reynolds CK, Huntington GB, Tyrrell HF, Reynolds PJ. Net portal-drained visceral and hepatic metabolism of glucose, 1-lactate, and nitrogenous compounds in lactating holstein cows. J Dairy Sci 1988;71:1803-12.

6. Huntington GB, Harmon DL, Richards CJ. Sites, rates, and limits of starch digestion and glucose metabolism in growing cattle. J Anim Sci 2006;84 (Suppl):E14-24.

7. Mashek DG, Beede DK. Peripartum responses of dairy cows fed energy-dense diets for 3 or 6 weeks prepartum. J Dairy Sci 2001;84:115-25.

8. Reynolds CK, Aikman PC, Lupoli B, Humphries DJ, Beever DE. Splanchnic metabolism of dairy cows during the transition from late gestation through early lactation. J Dairy Sci 2003; 86:1201-17.

9. Douglas GN, Overton TR, Ii HGB, Dann HM, Drackley JK. Prepartal plane of nutrition, regardless of dietary energy source, affects periparturient metabolism and dry matter intake in holstein cows. J Dairy Sci 2006;89:2141-57.
10. Janovick NA, Boisclair YR, Drackley JK. Prepartum dietary energy intake affects metabolism and health during the periparturient period in primiparous and multiparous Holstein cows. J Dairy Sci 2011;94:1385-400.

11. Rabelo E, Bertics SJ, Mackovic J, Grummer RR. Strategies for increasing energy density of dry cow diets. J Dairy Sci 2001; 84:2240-9.

12. Agenäs S, Burstedt E, Holtenius K. Effects of feeding intensity during the dry period. 1. Feed intake, body weight, and milk production. J Dairy Sci 2003;86:870-82.

13. Dann HM, Litherland NB, Underwood JP, et al. Diets during far-off and close-up dry periods affect periparturient metabolism and lactation in multiparous cows. J Dairy Sci 2006; 89:3563-77.

14. Guo J, Peters RR, Kohn RA. Effect of a transition diet on production performance and metabolism in periparturient dairy cows. J Dairy Sci 2007;90:5247-58.

15.FASS. Guide for the care and use of agricultural animals in research and teaching. 3rd ed. Champaign, IL, USA: Federation of Animal Science Societies (FASS); 2010.

16.Zom RLG, van Baal J, Goselink RMA, Bakker JA, de Veth MJ, van Vuuren AM. Effect of rumen-protected choline on performance, blood metabolites, and hepatic triacylglycerols of periparturient dairy cattle. J Dairy Sci 2011;94:4016-27.

17.Goselink RM, van Baal J, Widjaja HC, et al. Effect of rumenprotected choline supplementation on liver and adipose gene expression during the transition period in dairy cattle. J Dairy Sci 2013;96:1102-16.

18. Livak KJ, Schmittgen TD. Analysis of relative gene expression data using real-time quantitative PCR and the 2(-Delta Delta C(T)) method. Methods 2001;25:402-8.

19.Zhang Q, Su H, Wang F, Cao Z, Li S. Effects of energy density in close-up diets and postpartum supplementation of extruded full-fat soybean on lactation performance and metabolic and hormonal status of dairy cows. J Dairy Sci 2015;98:7115-30.

20. Ospina PA, Nydam DV, Stokol T, Overton TR. Evaluation of nonesterified fatty acids and $\beta$-hydroxybutyrate in transition dairy cattle in the northeastern United States: Critical thresholds for prediction of clinical diseases. J Dairy Sci 2010;93: 546-54.

21.Douglas GN, Overton TR, Drackley JK. Peripartal metabolism and production of holstein cows fed diets supplemented with fat during the dry period. J Dairy Sci 2004;87:4210-20.

22. Roche JR. Milk production responses to pre- and postcalving dry matter intake in grazing dairy cows. Livest Sci 2007;110: 12-24.

23. Alharthi A, Zhou Z, Lopreiato V, Trevisi E, Loor JJ. Body condition score prior to parturition is associated with plasma and adipose tissue biomarkers of lipid metabolism and inflammation in Holstein cows. J Anim Sci Biotechnol 2018;9:12.

24. Salin S, Vanhatalo A, Elo K, Taponen J, Boston RC, Kokkonen T. Effects of dietary energy allowance and decline in dry matter 
intake during the dry period on responses to glucose and insulin in transition dairy cows. J Dairy Sci 2017;100:5266-80.

25. Holtenius K, Agenäs S, Delavaud C, Chilliard Y. Effects of feeding intensity during the dry period. 2. Metabolic and hormonal responses. J Dairy Sci 2003;86:883-91.

26. Bobe G, Velez JC, Beitz DC, Donkin SS. Glucagon increases hepatic mRNA concentrations of ureagenic and gluconeogenic enzymes in early-lactation dairy cows. J Dairy Sci 2009;92:50929.

27. De KJ, Van dBW, Hulpio L, et al. Influence of adipocyte size and adipose depot on the in vitro lipolytic activity and insulin sensitivity of adipose tissue in dairy cows at the end of the dry period. J Dairy Sci 2016;99:2319-28.

28. Jaakson H, Karis P, Ling K, et al. Adipose tissue insulin receptor and glucose transporter 4 expression, and blood glucose and insulin responses during glucose tolerance tests in transition Holstein cows with different body condition. J Dairy Sci 2018; 101:752-66.

29. Collins S, Kuhn CM, Petro AE, Swick AG, Chrunyk BA, Surwit RS. Role of leptin in fat regulation. Nature 1996;380:677.
30. Mann S, Urh C, Sauerwein H, et al. Short communication: The association of adiponectin and leptin concentrations with prepartum dietary energy supply, parity, body condition, and postpartum hyperketonemia in transition dairy cows. J Dairy Sci 2018;101:806-11.

31.Loor JJ, Dann HM, Everts RE, et al. Temporal gene expression profiling of liver from periparturient dairy cows reveals complex adaptive mechanisms in hepatic function. Physiol Genomics 2005;23:217-26.

32.Castañeda-Gutiérrez E, Pelton SH, Gilbert RO, Butler WR. Effect of peripartum dietary energy supplementation of dairy cows on metabolites, liver function and reproductive variables. Anim Reprod Sci 2009;112:301-15.

33. Greenfield RB, Cecava MJ, Donkin SS. Changes in mRNA expression for gluconeogenic enzymes in liver of dairy cattle during the transition to lactation. J Dairy Sci 2000;83:1228-36.

34. Laguna JG, Cardoso MS, Lima JA, et al. Expression of hepatic genes related to energy metabolism during the transition period of Holstein and $\mathrm{F}_{1}$ Holstein-Gir cows. J Dairy Sci 2017;100: 9861-70. 